\title{
LA TESIS DE LA ÉTICA PROTESTANTE DE WEBER EN CINCO PASOS*
}

James J. Chriss

" DOI: https://doi.org/10.18601/01245996.v23n45.03. Recepción: 21-012021, aceptación: 02-06-2021. Sugerencia de citación: Chriss, J. J. (2021). La tesis de la ética protestante de Weber en cinco pasos. Revista de Economía Institucional, 23(45), 23-41. Este artículo se publicó en Academicus International Scientific Journal, 20, 51-65. Traducción de Alberto Supelano; se publica con autorización del autor.

a PhD. Profesor del Departmento de Criminología, Antropología y Sociología, Cleveland State University, Ohio, Estados Unidos. 


\section{La tesis de la ética protestante de Weber en cinco pasos}

Resumen Como resultado de muchos anos de leer y ensenar la famosa tesis de la ética protestante de Max Weber, he desarrollado un enfoque para cubrir este material, tanto en mis cursos de teoria de pregrado como de posgrado, que ha sido beneficioso para los estudiantes y les ha ayudado a dar sentido al complejo argumento desarrollado por Weber. Presento un modelo de trabajo de todas estas investigaciones académicas ligadas a la triada de la ciencia, que culminan en un enfoque de cinco pasos para organizar y explicar la tesis de Weber. Anado, ademas, una bibliografia comentada de reflexiones academicas sobre el trabajo de Weber en general y la tesis de la ética protestante en particular.

Palabras clave: Max Weber, ética protestante, idealismo, teología política, triada de la ciencia, teoría sociológica, llamado, profesión; JEL: A12, A13, N00, Z1, Z12, Z13

\section{Weber's Protestant ethic thesis in five steps}

Abstract As a result of many years of reading about and teaching Max Weber's famous Protestant ethic thesis, I have developed an approach to covering this material in both my undergraduate and graduate theory courses which has been beneficial to students and has helped them make sense of the rather complex argument developed by Weber. I provide a working model of all such scholarly inquires linked to the Science Triad, culminating in a five-step approach to organizing and explaining the Weber thesis. In addition, I provide an annotated bibliography of selected scholarly ruminations on Weber's work in general and the Protestant ethic thesis in particular.

Keywords: Max Weber, Protestant ethic, idealism, political theology, science triad, sociological theory; calling; JEL: A12, A13, N00, Z1, Z12, Z13

\section{Tese de ética protestante de Weber em cinco etapas}

Resumo Como resultado de muitos anos lendo e ensinando a famosa tese de Ética Protestante de Max Weber, desenvolvi uma abordagem para cobrir este material, tanto em meus cursos teóricos de graduação quanto de pós-graduação, que tem sido benéfica tanto para alunos quanto para alunos. eles dão sentido ao argumento complexo desenvolvido por Weber. Apresento um modelo de trabalho de todas essas investigações acadêmicas vinculadas à tríade da ciência, culminando em uma abordagem de cinco etapas para organizar e explicar a tese de Weber. Além disso, acrescento uma bibliografia comentada de reflexões acadêmicas sobre a obra de Weber em geral e as teses da ética protestante em particular.

Palavras-chave: Max Weber, ética protestante, idealismo, teologia política, tríade da ciência, teoria sociológica, vocação, profissão; JEL: A12, A13, N00, Z1, Z12, Z13 
T a Ética protestante y el espíritu del capitalismo de Max Weber es uno Lde los libros más destacados en los cursos de teoría sociológica a nivel de posgrado y de pregrado. De hecho, en su lista de los diez libros más importantes del siglo XX, la Asociación Internacional de Sociología menciona la Ética protestante en cuarto lugar, justo después de Economia y sociedad de Weber (n. $\left.{ }^{\circ} 1\right)$, La imaginación sociológica de Mills (n. ${ }^{\circ}$ 2) y Teoría social y estructura social de Merton (n. 3 ). En este artículo comparto con los lectores un enfoque para enseñar la Ética protestante de Weber que he desarrollado durante varios años. Mi enfoque consiste en dividir la teoría en partes discretas utilizando un enfoque de cinco pasos. Incluyo una gráfica que resume la teoría en un formato que los estudiantes han encontrado útil (de acuerdo con los comentarios en sus evaluaciones del curso de pregrado). Sin embargo, cuando enseñamos obras prestigiosas en teoría sociológica, a veces actuamos de manera muy dogmática en su apoyo y falta de compromiso con obras que critican y encuentran deficiencias en esos textos sagrados. Por ello, también incluyo una bibliografía comentada de análisis críticos seleccionados de la teoría de Weber. Esta discusión crítica sirve para involucrar a los estudiantes en las complejidades de lo que la teoría intenta lograr, mucho más que la aceptación incuestionable con que se suele tratar la teoría (en especial) en los cursos de pregrado.

\section{LOS INICIOS}

La ciencia comienza con una sensación de asombro, es decir, cuando se advierte una regularidad en el mundo social o físico que despierta la curiosidad sobre por qué y cómo funciona esa cosa o proceso observado (Stark, 2004). La sensación de asombro de Weber lo lleva a señalar que, hacia fines del siglo XIX, las estadísticas ocupacionales de Alemania y otros lugares sugerían que en los países de composición religiosa mixta, los de mayor nivel de empresa capitalista -dirigentes empresariales, propietarios de capital, así como empleados y gerentes con capacitación técnica y comercial, son abrumadoramente protestantes. En términos más específicos, que hay diferencias sustanciales en la posición económica y ocupacional de protestantes y católicos, y que como grupo los protestantes acumulan muchos más recursos económicos que los católicos. El sentido de asombro de Weber lo lleva a señalar algo sobre el capitalismo moderno: que ciertos grupos religiosos (protestantes) acumulan más propiedad económica que otros grupos religiosos (católicos). 
Para Weber, esta es la variable dependiente original o un resultado que requiere explicación. En esencia, Weber se interesa principalmente en explicar por qué ciertas ideas religiosas (principalmente el calvinismo) eran compatibles con un "espíritu capitalista" y cómo esto contribuyó al surgimiento del capitalismo. En adelante me referiré a la gráfica 1. El grupo de líneas superior representa el proceso real, desordenado y típicamente no lineal de construcción de la teoría. Estas después se reconstruyen en una teoría causal lineal que va desde la antigua noción de llamado hasta el capitalismo moderno (representada por la fila de flechas que apuntan a la derecha en la mitad de la gráfica $)^{1}$.

Gráfica 1

Tesis de la ética protestante de Weber en cinco pasos
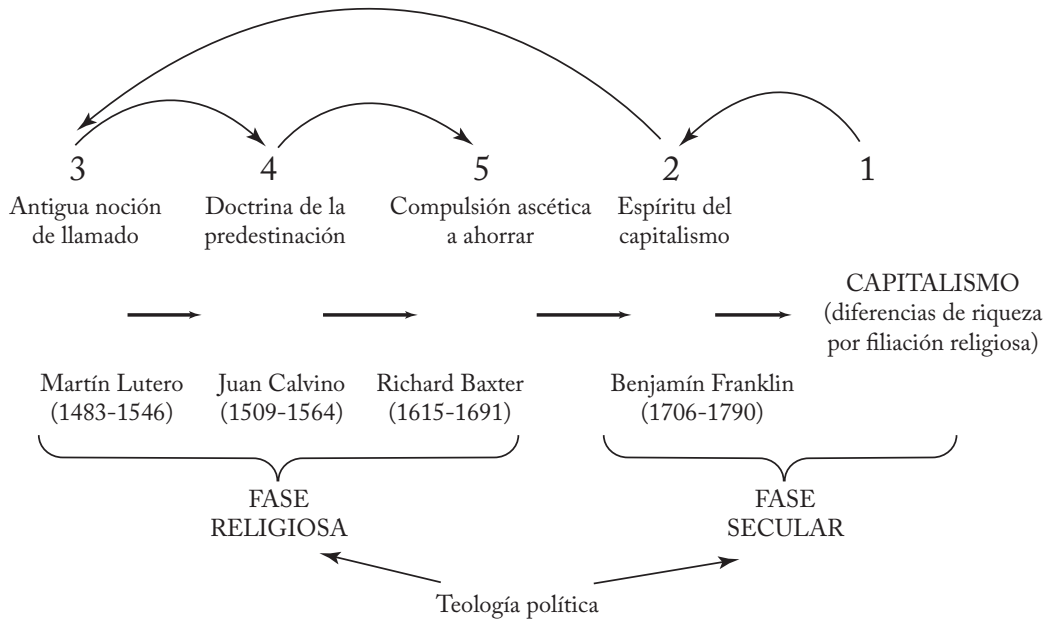

${ }^{1}$ Conforme a la traducción de Talcot Parsons, como traducción del término alemán Beruf el autor usa el término inglés calling, que en su sentido más antiguo tiene connotaciones religiosas: "una misión impuesta por Dios", y que después llegó a significar vocación o profesión ("la posición en la vida, precisa Weber”), un significado que nació con las traducciones de la Biblia, y que no correspondía al espíritu del texto original sino al espíritu del traductor. Aquí se utiliza el término "llamado" en el contexto religioso o luterano más tradicional y "profesión" cuando se hace referencia al calvinismo y a los escritos de Benjamín Franklin y posteriores, aunque salvo en las órdenes religiosas, en castellano este término ha perdido las connotaciones éticas y religiosas que aún persisten en alemán y en el término "vocación". Weber era consciente de los matices e imprecisiones de traducción y se refirió a ellos en las primeras páginas del capítulo tercero de la Ética protestante y el espiritu del capitalismo [N. del T]. 
Los cinco números debajo de las líneas de la parte superior representan los pasos principales en la construcción de la tesis de la ética protestante de Weber. El paso 1, en el extremo derecho, es la sensación de asombro de Weber, en términos de su apreciación de las diferencias de ingresos entre protestantes y católicos. Esto es lo que se debe explicar, y desde este punto el objetivo es descubrir los factores antecedentes que dan lugar al resultado o variable dependiente. La línea desde el paso 1 se remonta en el tiempo al espíritu del capitalismo, el cual es el paso 2. Este es el proceso de Weber de retroceso en el tiempo en busca de evidencia de las condiciones previas para el desarrollo del capitalismo moderno.

\section{FRANKLIN Y EL ESPÍRITU DEL CAPITALISMO}

Con el paso 2 Weber dirige su atención al concepto de espíritu del capitalismo. Este capitalismo se explica mejor haciendo referencia a ciertos documentos históricos. Weber cita específicamente algunas de las máximas más conocidas de Benjamín Franklin, como "el tiempo es dinero", "el crédito es dinero" y otros consejos específicos sobre el dinero y sobre la vida en general. Los escritos de Franklin son para Weber la encarnación de este espíritu del capitalismo.

Weber descubrió que, si bien Franklin no era un hombre religioso, su padre, un calvinista estricto, lo educó para que creyera que ganar dinero, si se hace legalmente, es la expresión de virtud y competencia en una profesión. De hecho, Weber sugiere que esta "idea peculiar", esta noción de deber personal en una profesión, es la ética social en la que descansa el capitalismo moderno. Aunque Weber estaba interesado en comprender el papel de las ideas religiosas en la producción del capitalismo, también reconoció que las condiciones históricas y materiales -como la revolución industrial, el surgimiento de un mercado libre y la creciente comercialización de la vida cotidiana- eran también importantes.

Por ello Weber sostiene que el espíritu del capitalismo (moderno) describe esa actitud "que busca ganancias de manera racional y sistemática de la manera que hemos ilustrado con el ejemplo de Benjamín Franklin” (1992, p. 64). Aquí Weber utiliza su metodología del tipo ideal para describir las características (ideales) del empresariado capitalista. Él o ella:

- evita el gasto extravagante e innecesario;

- evita el disfrute consciente del poder que le brinda su posición (estatus); 
- se avergüenza del reconocimiento social que recibe;

- lleva una vida de estricta disciplina (ascetismo intramundano), marcada por la modestia y la moderación;

- nada obtiene personalmente de su riqueza, salvo la sensación "irracional" de haber hecho bien su trabajo.

Weber también señala que durante eones la Iglesia desaprobó, o a lo sumo simplemente toleró, el impulso adquisitivo. Era muy probable que el capitalismo aventurero tradicional fuese condenado porque se lo consideraba enemigo del amor fraternal y de la caridad cristiana. ¿Cómo, entonces, una actividad que en una época fue condenada o apenas tolerada éticamente se convirtió en una profesión en el sentido de Benjamín Franklin? ¿Cómo fue posible que esa actividad al inicio dirigida únicamente al lucro luego se entendiera como una profesión con la que los individuos tienen una obligación ética?

Antes de abordar esta pregunta debo señalar que en la gráfica 1, arriba de los nombres de los cuatro personajes históricos en los cuales se basa Weber, figura el concepto clave asociado a cada uno. Para Franklin, es el espíritu del capitalismo. Además, en la parte inferior de la gráfica, la progresión de ideas en la formación de la teoría se divide en dos grandes movimientos: una fase religiosa anterior (de la antigua noción inicial de llamado a la compulsión ascética a ahorrar de Baxter), y una fase secular posterior (que comprende el espíritu del capitalismo de Franklin como predecesor inmediato del desarrollo del capitalismo moderno). A partir de este punto, la tarea de Weber es buscar un sistema (o sistemas) de creencias que precedan al capitalismo moderno e incorporen esta noción clave de deber en una profesión. Puesto que Franklin se educó en una tradición calvinista, Weber buscó evidencia del inicio de esta idea de profesión en la primera doctrina protestante.

\section{LA CONCEPCIÓN DE PROFESIÓN DE LUTERO}

Considerando la gráfica 1 , Weber da un gran salto hacia atrás en el tiempo, del paso 2 al paso 3 (ver la flecha en la parte superior de la gráfica), en busca de la expresión más temprana de una concepción religiosa de la profesión. Desde ese punto histórico inicial, Weber avanzó hasta llegar a la noción secular de profesión de Franklin (lo que lo llevó de los pasos 3 a 5). La profesión (Beruf), una concepción religiosa definida como una "tarea encomendada por Dios", prevaleció e incluso fue central en las sectas protestantes, y estuvo prácticamente ausente en la doctrina católica. Mientras que los católicos tendían a 
considerar que la vida ejemplar encarnaba en el ascetismo monástico (es decir, ultramundano), los protestantes consideraban que los verdaderos creyentes en la fe eran los que se esforzaban por cumplir sus obligaciones mundanas. En vez de retirarse del mundo, los protestantes adoptaron la noción de que las personas tienen el deber de trabajar en este mundo para construir el Reino de Dios en la tierra. Esta es, entonces, la máxima encarnación de la noción de profesión.

Para concretar esta noción de profesión, Weber examinó los escritos de Martín Lutero (1483-1546), un destacado teólogo alemán que lideró la Reforma protestante en Alemania. Sin embargo, aunque Lutero interpretó que la Biblia proporciona una sanción religiosa a la idea de deber en una profesión, su interpretación estaba impregnada de tradicionalismo. Como argumenta Weber, el tradicionalismo económico de Lutero era evidente en su sugerencia de que:

cada cual debe permanecer en la profesión y en el estado en que Dios le ha colocado de una vez para siempre y contener dentro de estos límites todas sus aspiraciones y esfuerzos en este mundo (1992, p. 85).

Este tradicionalismo de Lutero nunca podría existir en el espíritu empresarial típico del capitalismo moderno, de ahí que su noción inicial de un deber en una profesión sea un callejón sin salida. Esto significa que Weber ahora debe mirar más allá del luteranismo, a otras sectas protestantes, para encontrar una noción de profesión que se adapte más estrechamente al espíritu del capitalismo moderno.

\section{CALVINO Y LA PREDESTINACIÓN}

Weber encontró que encajaba mejor (el salto del paso 3 al paso 4 en la gráfica 1.) en los escritos de Juan Calvino (1509-1564), un notable reformador protestante francés, así como en otros puritanos, como Richard Baxter (que se discute más adelante). A través de estos escritos del calvinismo y las sectas puritanas se pueden reconstruir las conexiones entre la "vieja" ética protestante y el espíritu del capitalismo. En este sentido, Weber (1992, p. 90) afirma que "el siguiente estudio puede, por tanto, quizás en forma modesta, ser una contribución a la comprensión de la manera en que las ideas se convierten en fuerzas efectivas en la historia". Esto es emblemático de una corriente idealista en el pensamiento de Weber, una corriente que, contra el materialismo de Marx, argumentó que las ideas pueden tener una fuerza causal por derecho propio, hasta tal punto que ciertas condiciones materiales de nuestra existencia (p. ej., el capitalismo) se debieron en alguna medida a un sistema precedente de ideas (aquí, el calvinismo). 
El dogma más característico del calvinismo es la doctrina de la predestinación. La predestinación es la idea de que Dios, por razones desconocidas, eligió otorgar a una pequeña proporción de hombres y mujeres el don de la gracia eterna. No nos es posible entender el majestuoso plan de Dios; sólo sabemos que se salva una parte de la humanidad, y que el resto está condenado. Weber pidió que imagináramos el tormento personal, la angustia psicológica que esto impone a los verdaderos creyentes en la fe cuando contemplan su destino. Puesto que nadie podía saber con certeza si estaba entre los elegidos de Dios, los calvinistas naturalmente buscaron señales de gracia. En vez de revolcarse en la incertidumbre sobre si se está o no entre los elegidos, los calvinistas fueron instruidos para dedicarse a su trabajo y no dejar que la ociosidad y la tentación los desviaran. En vez de absorberse en la deidad bajo el luteranismo, bajo el calvinismo los hombres y mujeres serían conocidos por sus obras, no por cuánto oraran. Aunque las críticas a varios aspectos de la tesis de Weber se cubren en la bibliografía comentada; sobre este punto -que el protestantismo induce una ética de trabajo más fuerte- hay apoyo empírico reciente (ver, p. ej., van Hoorn y Maseland, 2013).

En esencia, los calvinistas se creían capaces de identificar la verdadera fe con el deber en una profesión, la cual servía para aumentar la gloria de Dios a través de esos trabajos. La convicción de que el deber en una profesión sirve a los propósitos superiores de Dios y es también un signo de elección inculcó en los calvinistas una forma sistemática de autocontrol y condujo a una racionalización de la vida cotidiana. De hecho, el Dios del calvinismo exigió de sus creyentes no solo buenas obras, sino una vida de buenas obras combinadas en un sistema unificado. Como explica Weber (1992, p. 117), bajo el calvinismo "La conducta moral del hombre promedio fue así privada de su carácter sin plan y no sistemático y sometida a un método consistente para la conducta en su conjunto".

De ahí que los calvinistas y los puritanos se sometieran a un intenso autocontrol en la medida en que prestaban cuidadosa consideración a las consecuencias éticas de su acción. De hecho, la tarea más urgente era destruir el goce espontáneo e impulsivo, mientras que el medio más importante era poner orden en la conducta de su vida diaria. En muchos sentidos, la conducta de la vida cotidiana del puritano empezó a tomar el carácter de una empresa comercial. 


\section{BAXTER Y LA COMPULSIÓN ASCÉTICA A AHORRAR}

Ahora estamos listos para pasar del paso 4 al paso 5 de la gráfica 1 . Así como antes se basó en los escritos de Franklin, Lutero y Calvino, en esta última parte del argumento Weber se basa en Richard Baxter, un puritano inglés del siglo XVII, para ilustrar aún más la conexión entre las ideas religiosas fundamentales del protestantismo ascético, por un lado, y la conducta económica cotidiana, por el otro. Weber quedó especialmente impresionado por el énfasis de Baxter en la riqueza y su adquisición. Aunque acumular riqueza por los placeres mundanos que se derivan de ella es moralmente sospechoso, mantenerse activo en una profesión es tolerable e incluso loable, según Baxter. Esto nos lleva al primero de los ocho principios que Weber extrae de los escritos de Baxter sobre el ascetismo protestante y su conexión con la actividad empresarial:

- Pérdida de tiempo: el "primero y en principio más mortal de los pecados" es simplemente la pérdida de tiempo en cosas como charlas ociosas, lujos, dormir más de lo necesario y otras actividades de ocio.

- Contemplación inactiva: Baxter sugiere que la contemplación inactiva del mundo no tiene valor y que, salvo el domingo, el día de descanso, los verdaderos creyentes deben orientarse continuamente al cumplimiento activo de su deber en una profesión.

- Trabajo: Weber señala que el trabajo de Baxter está repleto de advertencias de que las personas deben realizar un trabajo físico o mental duro y continuo.

- Ascetismo sexual: del punto anterior se sigue que la actividad sexual solo se valora en el contexto de un matrimonio santificado por la iglesia.

- La riqueza no es una exención: incluso quienes acumulan grandes riquezas no deben dejarse tentar a la exhibición ostentosa de ocio o del gasto extravagante.

- La profesión como virtud ascética: el trabajo en sí mismo no es la clave; más bien es un trabajo "racional" en una profesión.

- Rentabilidad privada: si Dios da a uno de sus elegidos la posibilidad de obtener una ganancia, debe seguir el llamado y aprovechar la oportunidad.

- Ahorro: los creyentes en la fe son simples depositarios de los bienes que Dios pone en sus manos. Como buenos servidores, deben rendir cuentas de cada centavo que se les confía. No se debe gas- 
tar tonta ni imprudentemente; de hecho, tienen un deber con las posesiones.

Esta última característica del protestantismo ascético es especialmente significativa para el desarrollo del capitalismo. Como explica Weber:

Podemos resumir diciendo que el ascetismo laico del protestantismo actuaba con la máxima potencia contra el placer despreocupado de la riqueza, y restringía el consumo, es especial de artículos de lujo [...]; eliminaba todas las inhibiciones que la ética tradicional imponía a la adquisición de riqueza, rompía todos las cadenas al afán de lucro pues, pues no solo lo legalizaba sino que lo consideraba un precepto divino (en el sentido expuesto) (1992, pp. 170-171).

La campaña del protestantismo ascético contra las tentaciones de la carne, combinada con su mandato de trabajar en el mundo en una profesión, dirigió a los seguidores a limitar el consumo. El resultado práctico inevitable es obvio: la acumulación de capital mediante la compulsión ascética a ahorrar (paso 5).

Weber sugiere que el impulso religioso original hacia el ascetismo y el trabajo encarnado en los escritos de Baxter finalmente se desvaneció. Sin embargo, los comportamientos relacionados con estas ideas originales continuaron más allá del siglo XVII y se manifestaron en forma más secular, por ejemplo, en los escritos de Franklin, y luego se desarrollaron en lo que hoy conocemos como capitalismo moderno. Weber afirma que "cuando la búsqueda exaltada del reino de Dios se convirtió en una sobria virtud profesional, las raíces religiosas empezaron a secarse y a ser sustituidas por argumentos utilitarios (1992, p. 176).

La conclusión de Weber es que uno de los elementos fundamentales del espíritu del capitalismo moderno -la conducta racional basada en la idea de profesión-, nació del espíritu del ascetismo cristiano intramundano. Weber también lamenta que este ideal religioso original se haya desvanecido, porque en la era moderna ha producido un fetiche continuo de la acumulación de propiedad privada, en la medida en que la idea de profesión da paso al cálculo tosco de la ventaja y la maximización de las ganancias. Conduce a la jaula de hierro de la burocracia, del instrumentalismo y del cálculo estratégico de las ganancias como valor primordial y fundamental que guía nuestros asuntos. Weber lamenta este giro de los acontecimientos con una paráfrasis de Nietzsche: "Especialistas sin espíritu, hedonistas sin corazón: estas nulidades se imaginan haber ascendido a una nueva fase de la humanidad jamás alcanzada anteriormente" (1992, p. 182). 


\section{TEOLOGÍA POLÍTICA}

A comienzos del siglo XX, Carl Schmitt inició discusiones sobre teología política cuando proclamó que "todos los conceptos importantes de la teoría moderna del estado son conceptos teológicos secularizados" (2005, p. 36). Aunque Schmitt asistió a varios cursos de Weber en la Universidad de Múnich durante el semestre del invierno de 1919-1920, debido a que después sirvió como jurista y teórico político del partido nazi a principios de la década de 1930, es comprensible que muchos observadores eviten asiduamente establecer conexiones entre ambos (Derman, 2011; Mommsen, 1990).

No obstante, es probable que Weber haya influido en el pensamiento de Schmitt en algún grado, incluso cuando, por ejemplo, la teoría del Estado de cada pensador diverja más allá de su observación compartida de que los Estados operan en gran medida monopolizando el uso legítimo de la fuerza coercitiva (Magalhães, 2016). Pero hay algo cierto: la tesis de la ética protestante de Weber es un tipo de teología política basada en la definición de Schmitt. El epicentro de todo ello es la noción crucial de vocación (Beruf) que Weber rastrea hasta Lutero, pero ¿de dónde la tomó Lutero? En varias partes del libro, sobre todo en las notas a pie de página, Weber alude a ello y encuentra que la concepción limitada de profesión de Lutero se deriva del Nuevo Testamento, específicamente de la actitud indiferente de San Pablo hacia el deber en una vocación, lo que refleja un tradicionalismo que simplemente instruía a los verdaderos creyentes a esperar la venida del Señor en la posición en que fueron colocados (Weber, 1992, p. 84). De hecho, la afirmación de Weber de la indiferencia paulina contribuyó en gran medida a diferenciar el luteranismo de la noción calvinista posterior del llamado a través de la predestinación (Zafirovski, 2018). Si Weber interpretó bien o no a San Pablo sobre el tema del deber en una vocación (Beruf en alemán, $x \lambda \hat{\eta} \sigma ı \varsigma$ en griego) está más allá del alcance de este artículo (ver, p. ej., Frey, 2008), pero cabe debe mencionar brevemente el análisis de Giorgio Agamben (2005).

Mientras que Weber prestó poca atención a las implicaciones de la vocación en los textos de San Pablo que fueron escritos en griego koiné, en sus manos klesis (de la que se traduce el alemán Beruf) no se entiende como mera indiferencia escatológica (Agamben, 2005, pp. 20-24). Para Pablo, la iglesia (ekklesia), o comunidad mesiánica, es la vocación o tarea asumida en cualquier lugar y en todas partes; de allí las nociones después secularizadas de deber profesional o incluso de Grundnorm de Kant (imperativo categórico) que buscan domar o 
dirigir el tosco impulso de la voluntad (el decisionismo de Schmitt), están esencialmente informadas por lo teológico.

Aun así, más que Kant, la línea de pensamiento alemana más directa parte de la versión anterior de teología política de Hegel, que es en esencia una crítica social basada en una meta-teología ( $u$ onto-teología) que busca entender la conexión del espíritu universal con el ser trascendental en el desarrollo del llegar a ser -más que el ser- del mundo y de la realidad vivida. Este linaje va de Hegel a Weber y luego a Schmitt (Heron, 2018, p. 138). Este "panenteísmo dialéctico" hegeliano postula que el espíritu universal es inmanente en la autotrascendencia de la voluntad humana en la producción de la historia (Agar, 2015, p. 1093). Cabe señalar también que antecedente y coherente con esta línea de desarrollo alemana es la "nueva ciencia" de Giambattista Vico desarrollada en Italia a comienzos del siglo XVIII (para un resumen, ver Chriss, 2018, y Milbank, 1991).

\section{CONCLUSIÓN: ALGUNAS VOCES CRÍTICAS}

La principal razón para que la tesis de la ética protestante de Weber siga siendo un elemento básico en la enseñanza de la teoría sociológica a nivel de pregrado y de posgrado es que es un modelo de cómo el sentido propio de asombro lleva a desarrollar una explicación sistemática del objeto de ese interés o curiosidad. La reconstrucción lineal de la teoría de Weber (que se muestra en la mitad de la gráfica 1) es una de las teorías creativas más brillantes desarrolladas por un sociólogo. E1 argumento de que una idea religiosa particular -la antigua noción de llamado de Lutero (aunque estuviera impregnada de tradicionalismo) fue la condición antecedente del desarrollo de las sectas protestantes posteriores (en especial de la doctrina de la predestinación de Calvino) que luego llevó a los verdaderos creyentes a construir el Reino de Dios en la tierra a través de la actividad económica enfocada, la que a su vez lleva a la acumulación capitalista a través de la compulsión ascética a ahorrar (Baxter), y finalmente que estas actividades económicas se difundieran entre el público en general y culminaran en el desarrollo del capitalismo moderno en general, es una idea realmente audaz. Llevar a los estudiantes de sociología a través de estos cinco pasos clave puede inspirarlos no solo a pensar teóricamente sino a apreciar el papel de las ideas en la condición humana.

Sin embargo, habiendo dicho todo esto, hay que considerar otra cosa, y no es trivial. Sin importar cuán venerada sea una teoría en nuestra disciplina, siempre es justo preguntar: “¿Tenía razón Weber?” 
Otra forma de preguntar esto es: “¿La evidencia empírica apoya la tesis de la ética protestante de Weber?" La respuesta corta es "No, no la apoya, al menos no en su mayor parte". Esto plantea un dilema interesante. ¿Por qué debemos tomarnos la molestia de enseñar la tesis de la ética protestante de Weber cuando la evidencia empírica que la respalda es débil o inexistente? Esta pegunta nos lleva de vuelta a la declaración inicial de Merton (1968) sobre la distinción entre la sistemática y la historia de la teoría.

De acuerdo con Merton, la sistemática de la teoría tiene que ver con el modelo positivista estándar de lo que debería hacer cualquier ciencia: explicar los fenómenos y asegurar que se disponga de métodos para probar esas ideas explicativas contra la evidencia empírica. Esto significa que, en el sentido estricto de la sistemática, la teoría es un conjunto de enunciados relacionados lógicamente que, tomados en conjunto, pretenden explicar, predecir o estimar un rango de fenómenos. De hecho, al inicio de mis clases de teoría, presento la teoría de esta manera y continúo hablando sobre la importancia de tener siempre en mente la tríada de la ciencia, que ubica y define el papel de la teoría en cualquier actividad que pretenda llamarse ciencia (ver gráfica 2).

Las partes de la tríada de la ciencia son:

- Teoría: un conjunto de afirmaciones interrelacionadas que explican una variedad de fenómenos.

- Datos: patrones de evidencia empírica sobre algún fenómeno de interés para los investigadores.

- Métodos: técnicas para reunir datos (incluidos experimentos, encuestas, etnografía o lo que sea).

Gráfica 2

La tríada científica

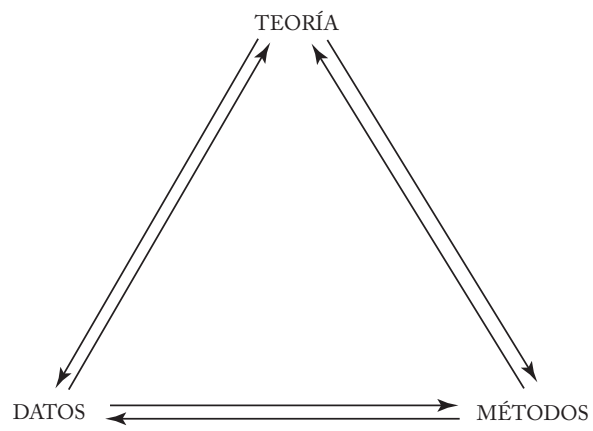


Ninguno de estos elementos de la tríada de la ciencia se sostiene por sí solo. Únicamente tienen sentido cuando se interrelacionan entre sí de manera específica. En este sentido de la sistemática de la teoría, la teoría solo "tiene sentido" en relación con su papel para ayudar a organizar los datos en patrones observables. La teoría por sí sola es relativamente inútil sin datos que muestren cómo encaja (la teoría) en el mundo. No obstante, Merton plantea que con el tiempo, en especial en sociología y algunas otras ciencias sociales, la sistemática ha sido superada por la historia, es decir, el proyecto de enseñar la teoría como historia de las ideas. En este caso, se puede justificar que el instructor dedique tiempo a circunstancias particulares -biográficas, culturales, históricas, políticas, económicas y psicológicas- que contribuyeron a producir la teoría o el programa conceptual particular. Este es el proyecto de la sociología del conocimiento, cuya hipótesis principal es que la teoría no es "acéfala" sino creada por seres humanos reales, de carne y hueso, que se esfuerzan por dejar su huella en el mundo. Como tal, la teoría es ideología, es decir, un proyecto público de persuasión marcado por un debate a veces rencoroso sobre la naturaleza de sus supuestos subyacentes, a menudo tácitos u ocultos (Gouldner, 1980).

El paso a tratar la teoría como historia, más que como sistemática, significa que la verificación o comprobación empírica de la teoría cumple un papel cada vez menos destacado en la enseñanza de la teoría sociológica. Para bien o para mal, el enfoque de la historia de las ideas ha triunfado y hoy está profundamente arraigado en la manera de enseñar la teoría en sociología. Pero incluso con este triunfo de la enseñanza de la sociología como historia de las ideas, aún hay intentos, dispersos aquí y allá, de probar o verificar qué tan bien concuerdan ciertas teorías sociológicas con la realidad empírica.

De hecho, Bargheer (2017) argumenta que el uso y la interpretación académicos de la tesis de la ética protestante de Weber han atravesado tres fases. La primera corresponde a la recepción, en gran parte en lengua alemana, de la tesis de Weber que apareció originalmente en artículos de las ediciones de 1904 y 1905 de la revista Archiv für Sozialwissenschaft und Sozialpolitik (Archivo de Ciencias Sociales y Políticas Sociales). Esta primera fase se ajusta más al modelo estándar de prueba de hipótesis en el proyecto de la ciencia empírica.

Esta fase dio paso a una segunda, iniciada en 1930 con la influyente traducción de Talcott Parsons de la tesis de Weber al inglés, que presentó su trabajo a una audiencia mundial más allá de Alemania. Para bien o para mal, esta segunda fase del estudio de Weber se centró más estrechamente en la teoría per se, lo que era consistente con el 
intento de Parsons de crear una teoría general de la sociología en la que el pensamiento de Weber tenía un papel destacado.

De acuerdo con Bargheer, la tercera fase coincidió con el giro de los sociólogos a prestar más atención al llamado problema micromacro, donde la tesis de Weber se interpreta como un intento de resolver el problema estructura versus agencia, con independencia de asuntos sustantivos específicos. En otras palabras, el foco específico de la solución que propuso Weber para explicar de qué manera el protestantismo inculcó una ética de trabajo particular que dio lugar al capitalismo, destacado en las dos primeras fases, en la tercera fase se enfocó en el proyecto general de vincular la volición individual, junto con las dotaciones culturales, cognitivas y motivacionales- a las estructuras sociales que abarcan y dan forma al dominio micro. Esto es similar a la división original idealismo-materialismo evidente desde el principio en el debate de Weber con el fantasma de Marx, pero actualizado en el lenguaje micro-macro.

Más adelante, presento la bibliografía comentada de libros y artículos seleccionados que prueban o critican varios aspectos de la tesis de la ética protestante de Weber y que son accesibles a estudiantes de teoría de pregrado y posgrado. No hay un conflicto necesario entre elogiar a Weber por la creatividad y el cuidado que puso en el desarrollo de su teoría, por un lado, y rechazar sus conclusiones, por otro lado (Barbalet, 2008; Greenfield, 2001). Ambos son objetivos pedagógicos importantes en la enseñanza de la tesis de la ética protestante de Weber.

\section{BIBLIOGRAFÍA GENERAL}

Agamben, G. (2005). The time that remains: A commentary on the letter to the Romans, P. Dailey, trad. Stanford, Ca.: Stanford University Press.

Agar, J. (2015). Hegel's political theology: 'True infinity', dialectical panentheism and social criticism. Philosophy and Social Criticism, 41(10), 1093-1111.

Barbalet, J. (2008). Weber, passion and profits. Cambridge, UK: Cambridge University Press.

Bargheer, S. (2017). The invention of theory: A transnational case study of the changing status of Max Weber's protestant ethic thesis. Theory and Society, 46, 497-541.

Chriss, J. J. (2018). Vico and the divine drama. Berlin Journal of Critical Theory, 2(3), 31-58.

Derman, J. (2011). Max Weber and charisma: A transatlantic affair. New German Critique, 38(2), 51-88. 
Ferrarotti, F. (2011). Bismarck's orphan: The modern world and its destiny, from disenchantment to the steel cage. Academicus International Scientific Journal, 2(4), 11-34.

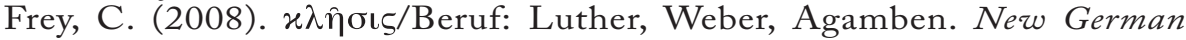
Critique, 35(3), 35-56.

Gouldner, A. W. (1980). The two Marxisms. Nueva York: Seabury Press.

Greenfield, L. (2001). The spirit of capitalism: Nationalism and economic growth. Cambridge, Mass.: Harvard University Press.

Heron, N. (2018). Liturgical power: Between economic and political theology. Nueva York: Fordham University Press.

Magalhães, P. T. (2016). A contingent affinity: Max Weber, Carl Schmitt, and the challenge of modern politics. Journal of the History of Ideas, 77(2), 283-304.

Merton, R. K. (1968). Social theory and social structure, enlarged ed. Nueva York: Free Press.

Milbank, J. (1991). The religious dimension in the thought of Giambattista Vico, 1668-1744, part 1: The early metaphysics. Lewiston, NY: Edwin Mellen Press.

Mommsen, W. J. (1990). Max Weber and German politics, 1890-1920 [1959], M.S. Steinberg, trad. Chicago: University of Chicago Press.

Parsons, T. (1935). H. M. Robertson on Max Weber and his school. Journal of Political Economy, 43(5), 688-696.

Schmitt, C. (2005). Political theology: Four chapters on the concept of sovereignty, G. Schwab, trad. Chicago: University of Chicago Press.

Van Hoorn, A. y Maseland, R. (2013). Does a Protestant work ethic exist? Evidence from the well-being effect of unemployment. Journal of Economic Behavior and Organization, 91, 1-12.

Weber, M. (1992). The Protestant ethic and the spirit of capitalism [1930], T. Parsons, trad. Londres: Routledge. Hay una edición crítica en castellano publicada en México por el Fondo de Cultura Económica en 2011.

Zafirovski, M. (2018). Calvinist predestination and the spirit of capitalism: The religious argument of the Weber thesis reexamined. Human Studies, 41, 565-602.

\section{BIBLIOGRAFÍA COMENTADA DE CRÍTICAS A WEBER}

Ascher, I. (2010). Max Weber and the 'spirit' of the Protestant ethic. Journal of Classical Sociology, 10(2), 99-108

Un argumento interesante centrado en la selectividad del enfoque de Weber, en la medida en que Weber considera evidente la interpretación que presenta con respecto a que los escritos de Franklin encarnan lo que él llama 'espíritu' del capitalismo moderno. Aunque gran parte de este argumento del espíritu vincula supuestamente el pensamiento de Franklin al establecimiento del capitalismo moderno, Weber nada dice o es inconsciente de la selectividad que guía el 'espíritu' de su propia interpretación del argumento de la ética protestante, incluido, por supuesto, el componente clave espiritual de los escritos de Franklin. 
Becker, G. (2009). The continuing path of distortion: The Protestant ethic and Max Weber's school enrolment statistics. Acta Sociologica, 52(3), 195-212

Becker sostiene que desde hace más de un siglo, los observadores de la tesis de Weber nunca han cuestionado un error evidente al comienzo del argumento de Weber. Weber afirmó que los protestantes ganaban más que los católicos, y que ingresaron en el tipo de escuelas que los predispuso a ser después empresarios exitosos mucho más que sus contrapartes católicas. Becker sostiene que esos errores en las estadísticas de matrícula escolar de Weber hacen discutible gran parte del resto del argumento.

Chalcraft, D. J. (2005) Reading Weber's patterns of response to critics of The Protestant Ethic: Some 'affinities' in and between replies to Felix Rachfahl and Werner Sombart. Journal of Classical Sociology, 5(1), 31-51

Chalcraft presta un valioso servicio resumiendo dos importantes líneas de críticas contra Weber elaboradas por Rachfahl y Sombart. (Para más información sobre Sombart, ver más adelante.) Rachfahl encuentra fallas en la afirmación de Weber de que los protestantes practicaban un ascetismo intramundano opuesto al ascetismo ultramundano (o monástico) de los católicos. Weber no consideró amablemente el debate "estéril" que Rachfahl inició sobre su definición de ascetismo, aunque el núcleo de esta discusión entre ambos puede ser valioso en la cobertura de la tesis de Weber.

Dickson, T. y MacLachlan, H. V. (1989). In search of the 'spirit of capitalism': Weber's misinterpretation of Franklin. Sociology, 23(1), 81-89 De modo similar al argumento de Ascher anterior, los autores afirman no tanto que Weber fue selectivo al considerar que Franklin encarnaba el espíritu del capitalismo moderno, sino que en muchos aspectos la interpretación de los pasajes clave de Franklin sobre dinero, tiempo y eficiencia era incorrecta. Según estos autores, Franklin era mucho más pragmático con respecto a su orientación al ahorro y la acumulación de lo que se guió por un ethos religioso, calvinista o de otro tipo. La crítica es que Weber vio demasiado en las palabras de Franklin, una mala interpretación que usó como evidencia de un 'espíritu' informado por la religión que nunca estuvo realmente allí.

Ghosh, P. (2014). Max Weber and the protestant ethic: Twin histories. Oxford, UK: Oxford University Press

Ghosh no es tan crítico de la tesis de la ética protestante de Weber per se, pro en cambio señala que la sociología del derecho de Weber, que destaca el derecho procesal sobre el derecho sustantivo (el primero más racional que el segundo), no cuadra con el presunto efecto del protestantismo ascético intramundano de orientar a los verdaderos creyentes hacia la salvación mediante la ansiedad por la predestinación. Esta tensión quizá proviene del "problema inglés" de Weber, en la medida en que no estudió el derecho natural en sus cursos de jurisprudencia en Alemania, sino que aprendió derecho a través de la escuela histórica del derecho prevaleciente en Alemania a finales del siglo XIX. En otras palabras, la noción de Ghosh de las historias 
gemelas con respecto a la obra de Weber es que su tesis de la ética protestante y su sociología del derecho finalmente llegan a un punto final común -bajo la apariencia del triunfo del protestantismo ascético en la producción del capitalismo-, pero que siguió rutas tortuosas y difíciles para llegar allí.

Hamilton, R. F. (1996). The social misconstruction of reality. New Haven, CT: Yale University Press

Hamilton encuentra falta de apoyo empírico a muchos aspectos de la tesis de Weber, incluido el de que los protestantes realmente sufrían ansiedad ante la predestinación como la describe Weber; no hay evidencia de que los protestantes vieran el trabajo como un signo de elección; y ninguna evidencia directa, solo una deducción, de que, en respuesta a las advertencias de Baxter desde el púlpito, incurrieran en niveles más altos de reinversión y ahorro en oposición a otras acciones (p. ej., acaparamiento, diezmo o filantropía).

Lehmann, H. (2005). Friends and foes: The formation and consolidation of the protestant ethic thesis. En Swatos, W.H. Jr. y Kaelber, L. (eds.). The protestant ethic turns 100 (pp. 1-22). Boulder, CO: Paradigm Publishers

Lehmann hace un excelente resumen de las respuestas de Weber a la primera ronda de críticas de su tesis que ocurrió entre 1907 y 1910. Los críticos clave a los que respondió Weber fueron H. Karl Fischer, un psicólogo, y Felix Rachfahl (quien se comenta en Chalcraft). Fischer cuestionó el método de Weber y su conclusión de que el ascetismo protestante inicial informó al "espíritu capitalista" secular posterior encarnado en los escritos de Franklin. Fischer pensaba que Weber carecía de un mecanismo psicológico adecuado para dar este salto, pues la ansiedad por la salvación quizá desapareció como motivador de la actividad económica con el amanecer del capitalismo industrial.

Robertson, H. M. (1933). Aspects of the rise of economic individualism: $A$ criticism of Max Weber and his school. Cambridge: Cambridge University Press

Robertson argumenta que la noción de profesión de Weber, que solo se encuentra en las sectas protestantes y que llevó a los verdaderos creyentes a empresas lucrativas, es demasiado estrecha. Da numerosos ejemplos de la literatura histórica que refutan la idea de que la profesión -labor continua y racional en el trabajo que redunda en gloria del Señor- solo surgió en el luteranismo y más tarde en el calvinismo. Para una enérgica defensa de Weber contra el argumento de Robertson, ver Parsons (1935).

Sombart, W. (1913). The Jews and modern capitalism, Epstein, M., trad. Nueva York: Dutton

Al contrario de Weber, Sombart argumentó que el judaísmo estuvo ligado mucho más fuertemente que el protestantismo al surgimiento del capitalismo industrial avanzado. Hasta su muerte en 1920, Weber mantuvo intensos debates con Sombart sobre este tema.

Stark, R. (2004). SSSR Presidential Address, 2004: Putting an end to ancestor worship. Journal for the Scientific Study of Religion, 43(4), 465-475 
Stark expresa una condena general a los académicos que tienden a aceptar irreflexivamente los escritos clásicos de Marx, Durkheim y Weber, y busca mostrar los aspectos de los escritos de cada uno de esos autores que son erróneos o mal orientados. Con respecto a la tesis de la ética protestante de Weber, que no es más más que un excurso anticatólico, Stark cita críticos que señalan que el capitalismo se desarrolló en Italia siglos antes de la Reforma protestante. También cita a otros críticos que argumentaron que el ascetismo intramundano no fue producto del calvinismo, sino que apareció mucho antes, entre sacerdotes monásticos ya en el siglo VI (p. ej., en San Benito, quien escribió, entre otras cosas: "La ociosidad es enemiga del alma"). 